\title{
A priority paper for the societal and ethical aspects of synthetic biology
}

\author{
Markus Schmidt • Agomoni Ganguli-Mitra • \\ Helge Torgersen · Alexander Kelle · Anna Deplazes • \\ Nikola Biller-Andorno
}

Received: 30 April 2009/Revised: 21 July 2009/Accepted: 22 July 2009

(C) The Author(s) 2009. This article is published with open access at Springerlink.com

\begin{abstract}
As synthetic biology develops into a promising science and engineering field, we need to have clear ideas and priorities regarding its safety, security, ethical and public dialogue implications. Based on an extensive literature search, interviews with scientists, social scientists, a 4 week long public e-forum, and consultation with several stakeholders from science, industry and civil society organisations, we compiled a list of priority topics regarding societal issues of synthetic biology for the years ahead. The points presented here are intended to encourage all stakeholders to engage in the prioritisation of these issues and to participate in a continuous dialogue, with the ultimate goal of providing a basis for a multi-stakeholder governance in synthetic biology. Here we show possible
\end{abstract}

M. Schmidt $(\bowtie) \cdot$ A. Kelle

Biosafety Working Group, Organisation for International

Dialogue and Conflict Management, Kaiserstr. 50/6,

1070 Vienna, Austria

e-mail: markus.schmidt@idialog.eu

URL: www.idialog.eu

A. Ganguli-Mitra $\cdot$ N. Biller-Andorno

Institute of Biomedical Ethics, University of Zurich,

Zollikerstr. 115, 8008 Zurich, Switzerland

H. Torgersen

Institute of Technology Assessment, Austrian Academy

of Sciences, Strohgasse, 45, 1030 Vienna, Austria

A. Kelle

Department of European Studies and Modern Languages,

University of Bath, Claverton Down, Bath BA2 7AY, UK

\section{A. Deplazes}

University Research Priority Programme (URPP) in Ethics, University of Zurich, Klosbachstr. 107, 8032 Zurich,

Switzerland ways to solve the challenges to synthetic biology in the field of safety, security, ethics and the science-public interface.

Keywords Synthetic biology - Governance - Biosafety · Biosecurity $\cdot$ Ethics $\cdot$ Science $\cdot$ Society

\section{Introduction}

The following priority paper has arisen from our 2-year European project SYNBIOSAFE (http://www.synbiosafe.eu), studying the ethical, safety and security aspects of synthetic biology. Based on an extensive literature search, interviews with scientists, social scientists, civil societies (Kelle 2007; Ganguli-Mitra et al 2009), a 4 week long public e-forum (Schmidt et al. 2008a), and consultation with several stakeholders (Schmidt et al. 2008b), the authors of this paper have compiled what they consider to be priority topics regarding societal issues of synthetic biology for the years ahead. The points collected below are intended to encourage all stakeholders to react to the various issues presented, to engage in the prioritization of these issues and to participate in a continuous dialogue, with the ultimate goal of providing a basis for a multi-stakeholder governance of this field. The points presented here might serve as well as a decision support for national and international funding agencies regarding future research on key societal aspects of synthetic biology. Last but not least we hope to enhance the discussion over the issues addressed.

Synthetic biology is the design and construction of new biological systems not found in nature. Synthetic biology as a scientific label currently includes the following subfields: (A) Engineering DNA-based biological circuits, including but not limited to standardized biological parts; (B) Defining a minimal genome/minimal life (top-down); (C) 
Constructing protocells, i.e. living cells, from scratch (bottom-up); (D) Creating orthogonal biological systems based on a biochemistry not found in nature, e.g. nonATGC DNA bases or non-DNA non-RNA nucleic acids, so called XNA (Xenonucleic acid) (Benner and Sismour 2005; O'Malley et al. 2008; Schmidt 2009; Herdewijn and Marliere 2009; Deplazes 2009). Also relevant to synthetic biology is a supporting technology, the chemical synthesis of DNA. Synthetic biology aims at creating novel organisms for practical purposes but also at gaining insights into living systems by re-constructing them. Synthetic biology is developing rapidly as a new branch of biotechnology, with many anticipated benefits and a high impact on society. As a result, the societal aspects of this discipline, as well as its possible risks, are becoming increasingly prominent. It is therefore crucial that the societal dimensions develop side by side with the field, engaging all stakeholders, including scientists, other experts and society at large.

The points made here address these dimensions in two ways. First they deal with novel issues that accompany synthetic biology, which are different from those associated with other life science activities. Second they also deal with the fact that "old" issues will resurface in the discussion of societal aspects of synthetic biology. Although some of the topics have been discussed for 30 years now (e.g. since Asilomar), the contemporary political and societal contexts are quite different compared to the mid-1970s (Berg 2008; Deplazes et al. 2009). Thus old issues may be renegotiated in the light of this contemporary context.

\section{Societal issues in synthetic biology: a priority list}

Below we present and discuss four major societal topics in synthetic biology: safety, security, ethics and the sciencesociety interface. A brief overview is given for each societal topic that reflects the outcome of the SYNBIOSAFE project and the consultation process with several stakeholders (see "Acknowledgements").

\section{Safety}

These points deal with the prevention of unintentional exposure to pathogens, toxins and otherwise harmful or potentially harmful biological material, or its accidental release.

\section{New methods in risk assessment}

Synthetic biology requires new methods of risk assessment to decide whether a new synthetic biology technique or application is safe enough (for human health, animals and the environment) for the use in restricted and/or less restricted environments. The following cases warrant a review and adaptation of current risk assessment practices: (A) DNA-based biocircuits consisting of a larger number of DNA 'parts'; (B) The survivability and evolvability of novel minimal organisms - used as platform/chassis for DNA based biocircuits-in different environments; and (C) Exotic biological systems based on an alternative biochemical structure, e.g. genetic code based on novel types of nucleotides, or an enlarged number of base pairs (NIH 2009; Schmidt et al 2008a; Schmidt 2009; Schmidt et al. 2009).

\section{Synthetic safety systems (biosafety engineering)}

An important task of a safety discussion is to explore how synthetic biology itself may contribute towards overcoming existing and possible future biosafety problems by contributing to the design of safer biosystems, for example: (A) Design of less competitive organisms by changing metabolic pathways; (B) Replacing metabolic pathways with others that have an in-built dependency on external biochemicals; (C) Design of evolutionary robust biological circuits; (D) Use of biological systems based on an alternative biochemical structure to avoid e.g. gene flow to and from wild species; (E) Design of protocells that lack key features of living entities, such as growth or replication (Schmidt 2009; Herdewijn and Marliere 2009).

\section{Diffusion of synthetic biology to amateur biologists}

Careful attention must be paid to the way synthetic biology skills diffuse (e.g. Do-it-yourself biology, amateurs, biohackers). The consequences of further deskilling biotechnology are not clear and should be investigated. In particular: (A) Care must be taken to ensure that everyone using the resources of synthetic biology does so safely and has sufficient awareness of and training in relevant biosafety techniques and approaches; (B) Proper mechanisms such as laws, codes of conduct, voluntary measures, access restrictions to key materials, institutional embedding and mandatory reporting to Institutional Biosafety Committees [IBCs], need to be in place to avoid unintentional harm (Schmidt 2008).

Security

These points deal with the prevention of misuse through for example loss, theft, diversion or intentional release of pathogens, toxins and other biological materials. Among the core areas of our research it is the security aspect that has been mostly absent from past discussions of the societal implications of the revolution in the life sciences.

\section{Awareness}

While biosecurity awareness among European DNA synthesis companies is comparatively high, among most 
European synthetic biology scientists it still is very low (Kelle 2007). Their awareness needs to be further enhanced through better communication and cooperation between the synthetic biology and biosecurity communities (NSABB 2008).

\section{Education}

Based on increased cooperation and communication among the synthetic biology and biosecurity communities, issues beyond the dual-use problem, such as the past misuse of the life sciences for offensive bioweapons programmes, security-related inadvertent research results, and the existence and operation of the Biological Weapons Convention should be systematically included in undergraduate biology curricula (Mancini and Revill 2008).

\section{Governance and oversight}

Addressing questions of governance and oversight of biosecurity will require more regulatory tools than dealing with other societal issues. In order to avoid too severe restrictions resulting from an oversight system, the continued and expanded involvement of all stakeholders is required (Anon 2008; Garfinkel et al. 2007; Kelle 2009).

\section{Technical solutions}

Some biosecurity challenges need immediate technical attention, as well as solutions to be further developed and implemented. This includes, in particular: (A) the cooperation of DNA synthesis companies (that produce gene- or genome-length DNA) in screening orders to avoid inadvertent production of certain select agents and/or parts thereof, (B) further developing and improving the technical means (e.g. software, databases) used to screen for DNA orders and (C) when expanding current efforts in these areas, such as to include shorter DNA strands, and possibly equipment such as DNA synthesizers in the future, a balance will need to be struck between security gains on one hand and practicability and usefulness on the other (Bernauer et al. 2008; Nouri and Chyba 2009).

\section{Ethics}

These points deal with normative aspects of procedures, applications and the distribution of synthetic biology.

\section{Designing and creating life}

The aim to design and create new forms of life raises per se certain ethical questions related to the relationship between humans and other living organisms and the moral status of the products of synthetic biology. Along the same line further societal discussion is required on various conceptions of life. Although such discussions are unlikely to reach global consensus, a social and philosophical investigation that aims at including a variety of worldviews is necessary, with particular attention being given to the normative implications arising from different conceptions of life (Ganguli-Mitra et al. 2009; Parens et al. 2008; Boldt and Müller 2008, 2009; Schmidt et al. 2009; Deplazes et al. 2009).

\section{Assessing risks and benefits}

An open and engaged ethical debate is needed on the moral acceptability of the risks and the equitable distribution of risks and benefits arising from various techniques and applications, in particular those requiring the interaction of natural and synthetic organisms, as well as the implications of such interaction for human health, animal health and for the environment.

\section{Benefits, access and justice}

Further discussion should be encouraged on the distribution of products and knowledge arising from synthetic biology research, in particular as they relate to various aspects of social justice, power relations and the current global divide. Particular attention should be given to the debate about intellectual property rights and the effect of such rights on access to the products and knowledge of synthetic biology (Rai and Boyle 2007; Henkel and Maurer 2007; ETC 2007, 2008).

Science-public interface

\section{Education}

Societal topics related to synthetic biology, such as safety, security and ethical issues as discussed should be incorporated into the teaching curricula of synthetic biologists from the very early days of their education.

\section{Public engagement}

Rendering scientists aware of such issues is a necessary condition but not sufficient to ensure that they are dealt with adequately. As synthetic biology develops into an applied technology, it is important that scientists, stakeholders and the public communicate in an interactive way. Past debates on genetic engineering suggest that in order to omit exaggerated hopes and fears, scientists should adopt an open approach towards the public and that stakeholders need to be responsive to scientific arguments. Both stakeholders 
and scientists should engage in ethical discussions with members of the public, going beyond mere campaigning or conveying of factual information. Views of the public reflecting public preferences and situated knowledge (embedded in language, culture, or traditions) need to be taken seriously, even if experts consider them to be misinformed. Different interests and world-views associated with technology and innovation, need to be addressed and not to be dismissed as unscientific.

\section{Stakeholder involvement}

Since developments in synthetic biology are so rapid and regulation alone is no guarantee against misuse or societal controversies, it is necessary to involve relevant stakeholders in the decision-making process. This allows for a flexible and relatively swift way of dealing with upcoming problems through a combination of regulations, agreements, codes of conduct etc. and entails a distribution of responsibilities. A multi-stakeholder approach for the governance of synthetic biology and its applications should involve scientists, regulators, members of civil society, industry representatives, philosophers, and other relevant groups (Ganguli-Mitra et al. 2009; Stemerding et al. 2009).

Acknowledgements The authors of this paper would like to acknowledge the participation of the following people in the refinement of this priority paper and thank them for their valuable contributions and comments (in alphabetic order): Mark Bedau, Joachim Boldt, Hans Bügl, Jane Calvert, Rocco Casagrande, Alison Cooper, Peter Dabrock, Antoine Danchin, Gerald Epstein, Markus Fischer, Sibylle Gaisser, Michele Garfinkel, Greg Kaebnick, Ellen Kennedy, Vasily Kuvichkin, Victor de Lorenzo, Bettye LS Maddux, Philippe Marliere, Steven Maurer, Andrew Maynard, Piers D Millett, Arun Mukhopadhyay, Frank Notka, Sven Panke, Eleonore Pauwels, James Revill, Eva Katharina Sinner, Ravi Srinivas, Dirk Stemerding, Jim Thomas, Jordi Vallverdú, Huib de Vriend, Ralf Wagner, Yanqing Wang, and Wei Wei. The work was supported by a EC-FP6 grant for the project "SYNBIOSAFE: Safety and Ethical Aspects of Synthetic Biology" (043205). For the final drafting of this manuscript, Markus Schmidt was supported by a grant of the FWF (Austrian Science Fund) project "Investigating the biosafety and risk assessment needs of synthetic biology in Austria (Europe) and China", project number I215-B17.

Open Access This article is distributed under the terms of the Creative Commons Attribution Noncommercial License which permits any noncommercial use, distribution, and reproduction in any medium, provided the original author(s) and source are credited.

\section{References}

Anon (2008) Nature (editorial). Pathways to security. Nature 455: 432 Benner SA, Sismour AM (2005) Synthetic biology. Nat Rev Gen 6:533-543

Berg P (2008) Meetings that changed the world: Asilomar 1975: DNA modification secured. Nature 455:290-291
Bernauer H, Christopher J, Deininger W, Fischer M, Habermeier P, Heumann K, Maurer S, Schwer H, Stähler P, Wagner T (2008) Technical solutions for biosecurity in synthetic biology. (Industry Association Synthetic Biology, Munich, Germany, 2008) Available via http://www.ia-sb.eu/wp-content/uploads/2008/09/ iasb_report_biosecurity_syntheticbiology.pdf. Accessed 30 April 2009

Boldt J, Müller O (2008) Newtons of the leaves of grass. Nat Biotech 26:387-389

Boldt J, Müller O (2009) Question of ethics. Science 323:339

Deplazes A (2009) Piecing together a puzzle. An exposition of synthetic biology. EMBO Rep 10(5):428-432

Deplazes M, Ganguli-Mitra A, Biller-Andorno N (2009) The ethics of synthetic biology. Chapter 5. In: Schmidt M, Kelle A, GanguliMitra A, de Vriend H (eds) Synthetic biology. The technoscience and its societal consequences. Springer, Berlin

ETC (2007) Extreme Genetic Engineering: an introduction to synthetic biology (ETC Group, Ottawa, Canada) Available via http:// www.etcgroup.org/upload/publication/pdf_file/602. Accessed 30 April 2009

ETC (2008). Commodifying nature's last straw? Extreme genetic engineering and the post-petroleum sugar economy. (ETC Group, Ottawa, Canada) Available via http://www.etcgroup.org/ en/materials/publications.html?pub_id=703. Accessed 30 April 2009

Ganguli-Mitra A, Schmidt M, Torgersen H, Deplazes A, BillerAndorno N (2009) Of Newtons and heretics. Nat. Biotech 27(4):321-322

Garfinkel MS, Endy D, Epstein GL, Friedman RM (2007) Synthetic Genomics: options for governance. (J.C.Venter Institute, Rockville, MD). Available via http://www.jcvi.org/cms/fileadmin/site/ research/projects/synthetic-genomics-report/synthetic-genomicsreport.pdf. Accessed 30 April 2009

Henkel J, Maurer S (2007) The economics of synthetic biology. Mol Syst Biol 3(117):1-4

Herdewijn P, Marliere P (2009) Toward safe genetically modified organisms through the chemical diversification of nucleic acids. Chem Biodivers 6:791-808

Kelle, A (2007) Synthetic biology \& biosecurity awareness in Europe. (Bradford Science and Technology Report No. 9, Bradford, UK. Available via http://www.synbiosafe.eu/uploads///pdf/SynbiosafeBiosecurity_awareness_in_Europe_Kelle.pdf. Accessed 30 April 2009

Kelle A (2009) Security issues related to synthetic biology. Chapter 7. In: Schmidt M, Kelle A, Ganguli-Mitra A, de Vriend H (eds) Synthetic biology. The technoscience and its societal consequences. Springer, Berlin

Mancini G, Revill J (2008) Fostering the biosecurity norm: biosecurity education for the next generation of life scientists. (Landau Network-Centro Volta, Como, Italy) Available via http://www. centrovolta.it/landau/content/binary/LNCV\%20-\%20BDRC_ Fostering\%20Biosecurity\%20Norm.pdf. Accessed 30 April 2009

$\mathrm{NIH}$ (2009) Notice of consideration of a proposed action under the NIH Guidelines Federal Register 74(41) (2009). Available via http:// www.thefederalregister.com/d.p/2009-03-04-E9-4618. Accessed 30 April 2009

Nouri A, Chyba CF (2009) Proliferation-resistant biotechnology: an approach to improve biological security. Nat Biotech 27(3): 234-236

NSABB (2008) Minutes of the National Science Advisory Board For Biosecurity. February 27-28, 2008. National Institutes of Health. Bethesda, Maryland. Available via http://oba.od.nih.gov/bio security/meetings/200802/2-27-28-08\%20NSABBRev1_12.01. 08\%20Minutes.pdf. Accessed 30 April 2009

O’Malley M, Powell A, Davies JF, Calvert J (2008) Knowledgemaking distinctions in synthetic biology. BioEssays 30(1):57-65 
Parens E, Johnston J, Moses J (2008) Ethics: do we need "Synthetic Bioethics"? Science 321:1449

Rai A, Boyle J (2007) Synthetic biology: caught between property rights, the public domain, and the commons. PLoS Biol 5(3): e58 doi:10.1371/journal.pbio.0050058

Schmidt M (2008) Diffusion of synthetic biology: a challenge to biosafety. Syst Synth Biol 2(1-2):1-6

Schmidt M (2009) Do I understand what I can create? Biosafety issues in synthetic biology. Chapter 6. In: Schmidt M, Kelle A, Ganguli-Mitra A, de Vriend H (eds) Synthetic biology. The technoscience and its societal consequences. Springer, Berlin

Schmidt M, Ganguli-Mitra A, Deplazes A (2008a) Towards a consensus paper guiding the development of synthetic biology. Paper presented at the SB 4.0 The fourth international meeting on synthetic biology, Hong Kong University of Science and Technology, October 10-12. 2008
Schmidt M, Torgersen H, Ganguli-Mitra A, Kelle A, Deplazes A, Biller-Andorno N (2008b) SYNBIOSAFE e-conference: online community discussion on the societal aspects of synthetic biology. Syst Synth Biol 2(1-2):7-17

Schmidt M, Dando M, Deplazes A (2009) Dealing with the outer reaches of synthetic biology. Biosafety, biosecurity, IPR and ethical challenges of chemical synthetic biology. In: Luisi PL (ed) Chemical synthetic biology. Wiley Publishing

Stemerding D, de Vriend H, Walhout B, van Est R (2009) Synthetic biology and the role of civil society organisatons. Chapter 10. In: Schmidt M, Kelle A, Ganguli-Mitra A, de Vriend H (eds) Synthetic biology. The technoscience and its societal consequences. Springer, Berlin 